\title{
Glasgow and Shanghai Cities as Learning Cities for Continuous Education: What Impact On Society as a Whole?
}

\author{
Sherwan T. Ameen, \\ University Assist Lecturer, \\ Researcher at PASCAL International Observatory, Iraq
}

Doi:10.19044/esj.2020.v16n13p101 URL:http://dx.doi.org/10.19044/esj.2020.v16n13p101

\begin{abstract}
Continuous education is focussed via the concerns of globalization, prompt transformation and the requirement aimed at public presence, national, regional and resident governments are altering their interpretation of education. That is why learning becomes the ambitions of governments to create cities of learning to reach the ultimate development in all sectors. In a continuously growing and complex world, the major cities are competing to become cities of learning, helping their citizens from all social levels and backgrounds. Construction a learning culture and brand lifelong learning an authenticity, it is significant to boost and attach entirely learning categories. Hence, learning is fundamental to attainment and prosperity, for individuals, families, communities, and nations worldwide. The key role of learning cities is to develop equality and economic stability, prosperity, personal fulfilment and mobilizes all their humans to reach full human potential. There are some key features and measurements of learning cities and challenges for each city to face for them to be considered as a learning city. Enabling citizens the opportunity to become literate is one of the most significant measures of the learning city. It should also encourage its citizens to be motivated to the building of their city. This paper focuses and assesses the examples of two cities from two different continents, namely Glasgow in the UK, Shanghai in China to evaluate the key features and different dimensions of these cities which are attempting to reach learning city status. Finally shaping some scopes for the policymakers and researchers around the world uncover the responses in continuing research to stretch the goals and critical features of learning cities. Personally the ideas of learning cities is a vital towards the supreme aim of education and more closely the lifelong learning as a whole package.
\end{abstract}

Keywords: Continuous education, learning cities, lifelong learning Shanghai and Glasgow learning cities 


\section{Learning cities and lifelong learning}

There is no single definition of a learning city; the concept appeals on theories about systems that promote innovation. The learning cities can be the response of the communities that aim to sustain the cherished beliefs, values and quality of life and environment as social or unique places. Cities are not simply places where people can live and work; they are also places to experience leisure, education, culture, and enterprise. To come across the needs and aspirations of citizens of a city of learning, the city should bring and unite all diverse providers of education for offering a local solution for the local challenge. The term learning in the phrase learning cities covers both individual and institutional learning. Individual learning refers to the skills and understanding of every individual, whether formally or informally. More specifically, it points to the lifelong learning not only the initial training and schooling. Through learning, individuals gain improved wages and more employment opportunities, in the meantime the society benefits by having flexible workplaces with up to date technology.

Several numbers of authors also in some detail summarize numerous transnational initiatives within the European domain in particular various initiatives of the OECD (2001) and the European Commission (O'Mahony, 2003). To have rich, free and significant learning in every part of their daily life offering them flexibility and equality (Storper, 1995) and more responsively "Open the doors to habits of learning" (Freire, 1998). Lately cities of learning used explicitly as a method of promoting regeneration, economic development and social cohesion which involves all sectors of the community (Han, 2013). It is obvious continuous education is driven by the strains of globalization, rapid change and the need for social inclusion, national, regional and local governments are transforming their view of education (Osborne, 2010). Osborne, et al. (2013, p. 409) suggest that "to build a learning society and make lifelong learning a reality, it is important to enhance and connect all learning types and places"

Furthermore, "Learning cities or communities promote learning and mobilize the sources of all five community sectors; civic, educational, economic, voluntary and environmental to enhance the Society's inclusivity and sustainability (Faris, 2007)". It is noteworthy that lifelong learning is not the only requirement to build the city of learning; the ability to deal with an international economy is significant too. The above perspectives uncover other strategies that are required for creating a city of learning. The most important challenge is to link the individual learning to a wider environment in which institutions are made aware of the need to innovate and learn to reach the target of a learning city (Longworth, 1999) (Yang, 2011). 'There are three areas related to the concept of a learning city or region which can make a difference, namely: economic issues, social issues, and intelligence, resource and 
networking issues of lifelong learning of cities and communities (Osborne, 2010)'". As mentioned in the introduction some key features and measurements are needed to create city globally competitiveness as well as knowledge-intensive industrial and service activities.

\section{Key features of learning city}

The development of the key features of learning cities is a normative tool for measuring them; it is the outcome of a long consultation process. In the beginning, UIL held a workshop in July 2012 to improve the framework of those key features. Some criteria endorsed at the workshop, which was inspired by the report of UN Analysing and Measuring Social Inclusion in Global Context (UNDESA, 2010) namely; ambitious but achievable, easy to measure, valid and reliable, crucial, relevant, clear and understandable. As shown in the following Figure, the framework of the key features of a learning city corresponds to the pediments, columns and foundation steps of the UNESCO logo:

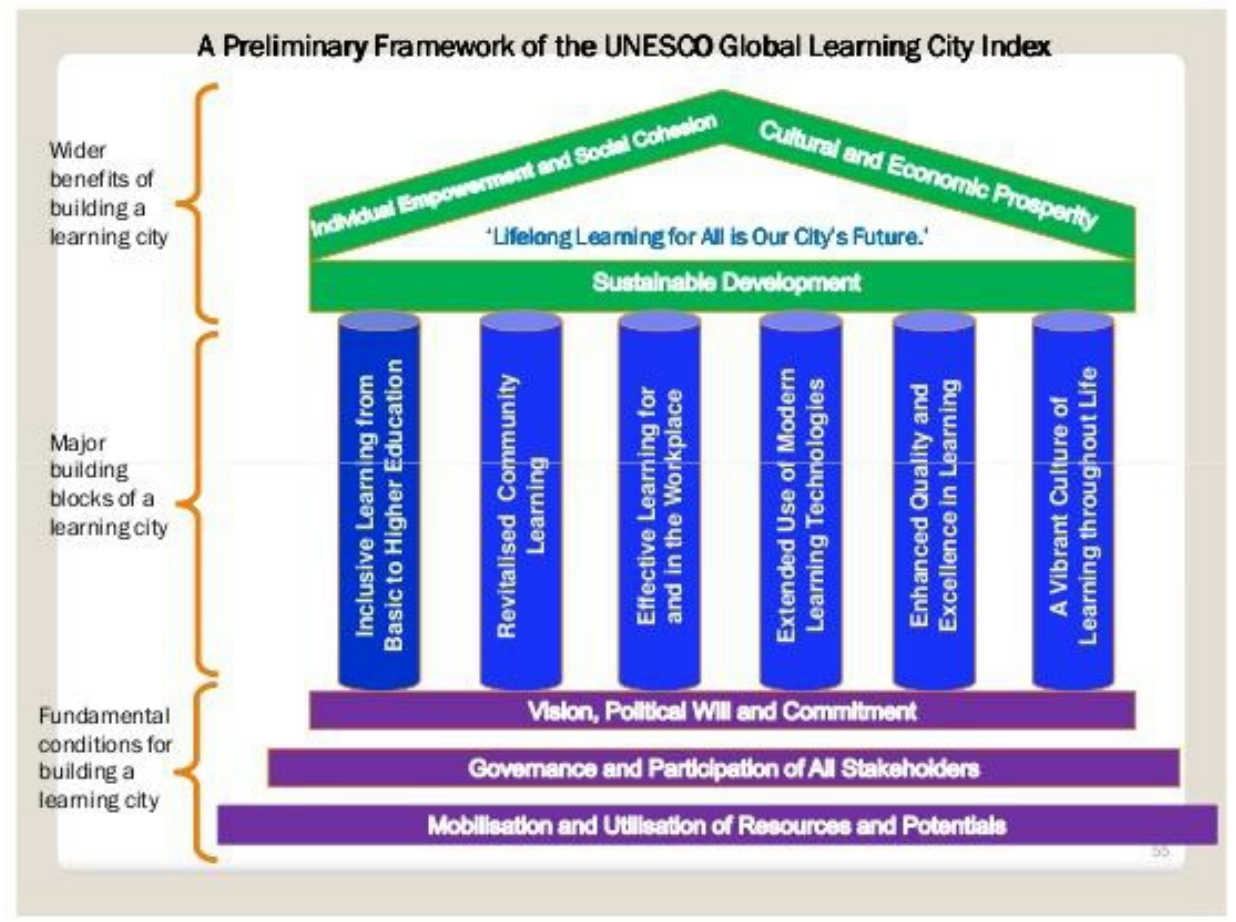

Figure 1: The framework of the key features of learning cities, UNESCO 2013.

The above diagram is split into three levels, the roof is the wider benefits of building a learning city, the pillars are the major building blocks and the most important are displayed at the bottom of the logo and are the 
fundamental conditions for building a learning city (Osborne, et al. 2013). There are 40 features and most of the features are quantitative, and associated with statistics that are provided by the responsible city authorities. As for qualitative features, some can be measured by the results of a survey conducted by independent professional agencies such as Gallop, whilst others can be measured through expert reviews provided by responsible city authorities. Many cities attempt to have the features of a leaning city to reach the highest development in all sectors. The target is to be competitive in a global marketplace through learning and innovation and to catch up with the new century demands of globalization. The following paragraphs will focus on some of the challenges faced by certain cities in their mission to become learning cities.

\section{Glasgow as a learning city}

Glasgow is Scotland's largest city with a population of 600,000 citizens and considered itself as a learning city in 1999 (Pascalobservatory, 2020). It is devoted to creating a learning city culture to reach prosperity in this complex international environment. It originated when it established the first Scottish parliament whose aim was to improve the welfare of its culture. The challenge that faces Glasgow is in understanding its socio-economic and historical developments (Clark, 2001). In 2000, educational disadvantages in north Glasgow were found to be the highest, including the increase rates of low skilled employments, increasing rates of illness and death, higher rates of public housing tenancy, poorer nutrition and high rates of crime and death (EUROlocal. 2010).

The initial steps towards Glasgow as a future city were taken and collaboration between the public and private sector was established to help the decision-making process aimed at its targets of a learning city and solve any barrier. Other improvements in Glasgow included IT literacy which raises the skills of the workforce and puts more people into learning. A great success turned out when REAL (the city-wide network of learning centres) designed in 1999 which included representatives from further and higher education, the City Council and Scottish Enterprise Glasgow. They aimed to provide Glasgow's citizens with the highest quality learning possible in accessible ways and at all levels. Within a year there were lots of learning centres in universities, small businesses, and libraries. It was regarded as a genuine network of learning centres. As a result of establishing REAL, the families enjoyed the computer rooms and learning activities together. The most recent initiatives taken were a drive to tackle illiteracy, for example, there were training literacy tutors for adults. A package of measures was introduced to encourage different target groups to make them lifelong learners. Other strategies were taken to increase the number of visitors to museums and 
galleries by which enhanced the reputation of the City for Excellence in Culture and Arts. (Cara et al, 2002) argue for the significant inclusion of a culture of learning into 'the genetic code' of the city.

\section{Glasgow future plans focus}

Recent examples include a ten-year improvement plan launched in 2006 and other strategies in 2010 establishing a super college, New Glasgow campus for creating a learning district in the city. Sankey et al. (2006) illustrated that the regional authorities must guarantee the activities of learning attract other sources whereby learning becomes the instrument of regeneration initiatives for addressing other areas of developments e.g. economic development, health, leisure, and planning. Continuous co-operation with the authorities is a major requirement to ensure the success of a learning city. The EcCoWell initiative widens the perspective of the learning city by introducing Learning Cities, Healthy Cities, and Eco-Cities and by bringing together the ecological, cultural, economic, community, lifelong learning and wellbeing strands of development in cities. The evidence would suggest that without a doubt, Glasgow is attempting to build a knowledge-based society with the best features of a learning city.

\section{Shanghai as a learning city}

Shanghai is the largest Chinese city by more than 24 million; a learning city Shanghai has experienced tremendous changes in the last one hundred years. It is also a city with a tradition of lifelong learning. It also becomes an extremely important source of continuous and endless development in building a learning city with world metropolis status (Salleh and Tan, 2013). In 1999 Shanghai's municipal government proposed that each citizen be enabled opportunities of learning in each stage of his or her learning. Institutions of higher education in Shanghai have provided citizens with various opportunities for learning such as continuing education of degree programs, professional education and other forms of leisure education. Students taking these forms of education have totalled 47,000 (ShanghaiGov, 2010). In communities, a learning network that covers the whole city of Shanghai has been developed. $91 \%$ of families have been able to learn over one hour every day and $88 \%$ of households have their special learning expenditure every year. On the internet learning resources, centres curricula supermarkets platforms, etc. have enabled up to one million learners to participate in on-line education among whom 350,000 are senior citizens.

\section{Shanghai strategies plans}

Today Shanghai has developed into a learning city that features educational integration and connectedness at each stage of one's life from the 
cradle to the grave. Led by the philosophy of lifelong learning education, educational fields that include pre-school education, basic education, professional education, higher education, and community education are achieving great transformation. In Shanghai, prescriptive, pre-school education means happiness and enlightenment. Community education for aged professionals and education for farmers all provide each member of the society with increasing opportunities for learning. A learning city should not only bestow the right of enjoying education on each citizen but create platforms of public service for the city that enables each individual to enjoy resources of high-quality education. Shanghai Open University caters to the demands of people, providing equal opportunity for all and promotes the development and strives to benefit more learners. Shanghai academic credit transfer and accumulation bank accrediting transferring and accumulating learning achievements of citizens. Educational alliances at all levels have enabled the development of the learning city of Shanghai which is a city full of vigour and vitality. The college training alliance which composed of over 20 colleges of continuing education from universities and colleges in Shanghai provides plenty of training programs for citizens on its initiative and has played positive roles in curriculum development, allocation of teachers, etc. Public, cultural resources such as libraries, museums of science and technology, cultural centres, stadiums, etc. are encouraged to provide public services for lifelong learning. Shanghai practice base for citizens' lifelong learning has been established which offers citizens endless fun through their experience of lifelong learning. The top-level design in 2006 the guiding ideas on the promotion of learning society by CPC Shanghai municipal committee and Shanghai municipal government was issued and hence the Shanghai Municipal Committee for the Promotion of Lifelong Learning Society and lifelong education that is composed of 20 municipal departments was established. In May 2011 the ordinance for the promotion of lifelong education in Shanghai was officially implemented. Shanghai's educational reform and development for long and medium-term planning were formulated. Here a nuclear idea for lifelong learning development for each student was put forward and recently Shanghai teens became the top in the international education ranking area (OECD, 2013). Learning provides a better life.

Shanghai shall further develop a lifelong system that meets high demand serving society and promoting development in the future, to achieve the objectives of establishing a learning city of world metropolis. Learning cities are initiatives that local governments have taken in response to economic pressures to increase local competitiveness. Continuous skill development is essential for both entering the workforce and for progressing beyond one's initial position. Sustainable economic growth depends on the input of lifelong learning systems. The interconnectedness, interdependency, and interaction of 
these social, economic and environmental factors will help prosper and develop our cities. The EC is currently funding a project called EURO local which is assessing the current situation within Learning Cities by examining their development and progress.

\section{Comparison synopsis of the two cities}

The two cities has been chosen as there are sitting ground plans for the learning cities as pioneers' cities in lifelong learning. In comparing the two cities there are some points to be considered;

\begin{tabular}{|l|l|}
\hline Shanghai focus & Glasgow focus \\
\hline $\begin{array}{l}\text { focuses on improving vocational training to } \\
\text { enhance the professional skills of its } \\
\text { employees and activate its economic sector }\end{array}$ & $\begin{array}{l}\text { Public awareness, education on } \\
\text { sustainability and city targets as well as its } \\
\text { government investment is all features of the } \\
\text { learning city of Glasgow }\end{array}$ \\
\hline $\begin{array}{l}\text { Enhances continuing education to train a } \\
\text { large number of professionals and it } \\
\text { strengthens rural education. }\end{array}$ & $\begin{array}{l}\text { networking through PASCAL is a good way } \\
\text { of it communicating its progress and allows } \\
\text { it to share good practice and learn from } \\
\text { others with similar aims }\end{array}$ \\
\hline $\begin{array}{l}\text { Shanghai approach is much more } \\
\text { systematic and organic }\end{array}$ & $\begin{array}{l}\text { made plans which are much more integrated } \\
\text { with its national policies such as its lifelong } \\
\text { learning policy }\end{array}$ \\
\hline
\end{tabular}

Its communities also have a voice in what is happening within its communities. One of the main goals of the learning cities is establishing Economic stability and Shanghai with its extensive efforts in achieving its learning city goals has established. Glasgow in comparison has a long way to go in fulfilling its learning city targets as national policies have diluted its city learning goals and more money needs to be invested into publicizing their national benefits so that they become the collective aims of society. As Scotland's devolved government continues to evolve, it needs to seriously consider putting forth substantial financial resources and considerable political effort into transforming Glasgow into a Learning City. Using examples of cities, such as Shanghai and others help to illustrate the potential benefits that learning cities could bring to improve living conditions, economic prosperity, and social cohesion in Glasgow.

\section{Inference and further continuous research recommendation}

To reach an assessment about the learning cities, it is essential to ask this question; what distinguishes a learning city from other cities? There is a range of answers to this question. In the learning cities the citizens are participating in determining the future of their city, so in that purpose new strategies introduced of lifelong learning at all levels and for all people in parity. Giving the citizens the competences to make good decisions and try to 
find a solution for problems and making life easier to ensure a high quality of learning.

Other advantages of a learning city are engaging the higher and further education, businesses, schools, and institutional stakeholders to contribute to the environment for social and economic developments and make the citizens' voice understood. Through active citizenship and volunteering individuals and communities contribute to the welfare of the other members in the city, and it should implement innovative strategies to mobilize and organize this effort (Clark, 2001). The local authority needs to understand and address its city's local, national and international sustainability and humanitarian problems. It's very important that the future of the learning cities is not just for the sake of the measurements but the focus should be made on the key underlying motivations of individuals participating in the learning. This is done through data collection and finding ways to motivate people and change people's behavior to invest in learning (Osborne et al., 2013).

The most important thing about the building blocks of learning cities is the elements of its foundation which can be the political will, commitment and a good system of governance. There is a lot of initiatives in building such cities such as the PASCAL initiative which is called learning 'cities together 2020' which makes a contemporary analysis of how well cities are doing towards their goals of becoming learning cities. The arguments for learning cities from an economic perspective suggest that competition in a global market is compromised because a skills deficit exists and that better-qualified individual are needed for the labour market. Further for individuals, there is an economic payoff in achieving higher qualifications and also by expanding the system of post-compulsory education a widening and an increase in social justice occurs as well as social inclusion and mobility. Opening training sessions for teachers, educators, and administrators to enable them to understand and use modern technologies that enhance learning is beneficial and guarantees that all citizens have flexible access to ICT tools and programs. In conclusion, the learning city is one with plans and strategies to encourage wealth, social cohesion, economic development, and personal growth through which the development of its citizens is achieved (OECD, 2013).

Finally, the question must be asked as to the measured outcomes of these learning city goals and the wider benefits they have on our societies as a whole. There are still many people interested in pursuing the answers to these questions from practitioners to policymakers and researchers all around the world. There are still interesting efforts as ever to uncover the answers in continuing research to reach the goals and ultimate features of learning cities. 


\section{References:}

1. Cara, C, Landry, C and Ranson, S, 2002.in, Cartwright, M, Edwards, $\mathrm{R}$ and Reeve, F (Eds), Supporting Lifelong Learning, Volume 2, Organising Learning, London, Routledge

2. Clark, J. , 2001. Glasgow the Learning City: Lifelong Learning and Regeneration, Glasgow, Scottish Enterprise

3. ShanghaiGov, 2010. Education In Shanghai. [online] Available at: http://www.shanghai.gov.cn/shanghai/node27118/node27880/u22ai6 5366.html [Accessed 15 March 2020].

4. EUROlocal. 2010. A Case Study Of Glasgow As A Learning City. [online] Available at: http://eurolocal.info/it/resource/case-studyglasgow-learning-city [Accessed 25 March 2020].

5. Faris, R ., 2007. Learning Communities: Webs of Life, Literacy and Learning, Halifax, Symposium on Learning Communities

6. Freire, P., 1998. Teachers As Cultural Workers. Letters To Those Who Dare Teach. The Edge: Critical Studies In Educational Theory. Westview Press.

7. Han, S. and Makino, A. 2013. Learning cities in East Asia: Japan, the Republic of Korea and China. International Review of Education, 59(4), pp.443-468.

8. Longworth, N and Osborne, M, 2010. Perspectives on Learning Cities and Regions, Leicester, NIACE

9. Longworth, N., 1999. Lifelong Learning at Work - Learning Cities for Learning Century, London, Kogan Page

10. OECD, 2001. Cities and Regions in the New Learning Economy, Paris: OECD.

11. OECD, 2013. Education at a Glance 2013: OECD Indicators, OECD Publishing

12. Osborne, M., Kearns, P. and Yang, J., 2013. Learning cities: Developing inclusive, prosperous and sustainable urban communities. International Review of Education, 59(4), pp.409-423.

13. O'Mahony, M., 2003. EU Productivity And Competitiveness. Enterprise Publications.

14. Salleh, H. and Tan, C., 2013. Novice Teachers Learning from Others: Mentoring in Shanghai Schools. AJTE, 38(3).

15. Pascalobservatory, 2020. Glasgow As A Learning City: Towards A Renewed Vision $\mid$ PIE. [online] Available at: http://pie.pascalobservatory.org/pascalnow/pascalactivities/news/glasgow-learning-city-towards-renewed-vision [Accessed 31 March 2020].

16. Sankey, K, and Osborne, M., 2006. ifelong Learning, Reaching Regions Where Other Learning Doesn't Reach, in, Edwards, R et al, 
Researching Experiential and Community-Based Learning, London, Routledge

17. Storper, M., 1995. The Resurgence of Regional Economies, Ten Years Later: The Region as a Nexus of Untraded Interdependencies. European Urban and Regional Studies, 2(3), pp.191-221.

18. UNDESA, 2010. Analysing And Measuring Social Inclusion In A Global Context. [online]

Available

at:

https://www.un.org/esa/socdev/publications/measuring-socialinclusion.pdf [Accessed 25 March 2020].

19. UNESCO, 2013a. Key Features of Learning Cities - Introductory Note. Hamburg: Unesco Institute for Lifelong Learning.

20. Yang, J., 2011. Perspectives on learning cities and regions: Policy, practice, and participation. International Review of Education, 57(34), pp.517-519.

\section{Appendix A}

The framework of the key features of learning cities, UNESCO 2013 